\title{
Improving the design of artwork and jewelry made of chalcedony
}

\author{
Vladislav Zhukov ${ }^{1}$, Lyubov Zhukova ${ }^{1}$, and Ksenia Ponomareva ${ }^{1, *}$ \\ ${ }^{1}$ St. Petersburg State University of Industrial Technologies and Design, 18, Bolshaya Morskaya St., \\ St. Petersburg, Russia
}

\begin{abstract}
The study is devoted to the development of technology to enhance the aesthetic characteristics of design objects made of chalcedony. These techniques can be applied to stone figurines and jewelry. An algorithm for designing products based on the properties and processing technologies of stone material is proposed. The surface decoration of a product made of chalcedony consists in the possibility of changing color, drawing a pattern and adding a texture. Two methods for changing the color of chalcedony have been studied - heat treatment and impregnation. The essence of the method of impregnation is the holding of the stone in a coloring solution at a temperature of $90{ }^{\circ} \mathrm{C}$ for 170 hours. The heat treatment method consists in processing chalcedony at a temperature of $350{ }^{\circ} \mathrm{C}$, the duration of the temperature exposure is in the range of 5 to 20 hours. When dyeing samples of gray chalcedony, a color spectrum is obtained in the range of wavelengths from 582 to $590 \mathrm{~nm}$. The formation of a smooth texture with various tools and materials of different grain sizes made it possible to obtain surface quality in the range of $1.1-0.02$ microns. The technologies of drawing a pattern on the surface of chalcedony are revealed: etching, laser processing and local dye impregnation. When applying laser processing and etching, a white rough pattern is formed. Using local impregnation allows creating a color pattern on the surface of chalcedony. Results. The use and combination of the described technologies for decorating chalcedony allows creating the desired aesthetic characteristics of lapidary works of art.
\end{abstract}

\section{Introduction}

In modern lapidary and jewelry production, more than a hundred varieties of gems are used, which are classified as colored stones. There are three groups: jewelry, jewelry-ornamental and ornamental minerals. Distinctive characteristics of this group of minerals are saturated color, decorative texture, the ability to be polished, high strength and other properties that provide high aesthetic and strength characteristics of these materials. The jewelryornamental stones, often used in lapidary and jewelry art, include minerals of the chalcedony group. This group of minerals is used for the manufacture of cabochon inserts, beads or highly artistic products (cameos, bowls, figurines, etc.), as well as collectible, facing and technical materials. Thus, in the whole variety of types of stone products - from

\footnotetext{
*Corresponding author: ksups2005@gmail.com
} 
architecture to jewelry and technical products, there is frequent use of chalcedony. Chalcedony has a high hardness and, as a result, the ability to withstand delicate relief and polishing; bright color, diverse appearance, and territorial prevalence. Deposits of one or another mineral of the chalcedony group exist in different countries, including in Russia (Transbaikalia, Siberia, Karelia, Crimea, the Caucasus, etc.). Interest in agates and chalcedony has been observed for many centuries in different countries of the European and Eastern world. Despite the widespread occurrence of chalcedony in nature, its industrial accumulation with high decorative and technological characteristics is a rarity represented by small deposits, where the amount of raw materials with high decorative and physicomechanical characteristics does not exceed 30\%. Accordingly, the development of technology to enhance the decorative properties of low-grade chalcedony contributes to the involvement of the maximum amount of raw gemstones in the processing, which ensures the conservation of natural resources and the expansion of the range of stone products. Nowadays, technologies for decorating raw gemstones in design objects are not well studied. There is a need to create a scientific and methodological base that provides modeling of design objects made of stone and control the decorative properties of the material. The development of jewelry design is aimed at an active search for new artistic, material and technological solutions that contribute to improving the aesthetic characteristics of design objects and become the subject of scientific research. (German, 1998; Sbornicchia, Montesperelli, Ingo \& Gusmano, 2004; Kautek, 2010; Tiberto \& Klotz, 2012; Eyssautier-Chuine, Mouhoubi, Reffuveille \& Bodnar, 2019).

The aim of the work is to develop technology for decorating chalcedony to improve the aesthetic properties of design objects and increase the competitiveness of products.

The object of the study is the process of decorating the surface of chalcedony in design products.

The subject of the study is the qualitative and quantitative characteristics of the color change of chalcedony, its surface structure and texture.

Chalcedony is one of the varieties of silica (O'Donoghue, 1990; Fallick, Jocelyn, Donnelly, Guy \& Behan, 1985; Powolny, Dumańska-Słowik, Sikorska-Jaworowska \& Wójcik-Bania, 2019), namely, the cryptocrystalline fibrous group of low-temperature formation $\left(300-400{ }^{\circ} \mathrm{C}\right)$ of $\alpha$-quartz. Chalcedony is silicon dioxide represented by the chemical formula: $\mathrm{SiO} 2$ (46.7\% of silicon and $53.3 \%$ of oxygen). The composition of the impurities depends on the composition of the medium in which the mineral was formed. The structure of cryptocrystalline quartz can be fine-grained and fibrous. When polished, chalcedony has a glass luster, in its natural state - waxy. The hardness on the F. Mohs scale is $6.5-7$ points. Density: $2.58-2.66 \mathrm{~g} / \mathrm{cm}^{3}$. Cleavage is absent, fracture: uneven, shell-like. Light refraction: 1.530-1.540. Dispersion and pleochroism are absent (Moxon, T. 2002; Schumann, 2010). The degree of transparency is variable: from translucent in thin plates to opaque. The mineral group of chalcedony includes such minerals as agate, chrysoprase, carnelian, sapphirine, plasma, linkurium, etc. The above types of chalcedony have wide color and texture ranges.

Chalcedony belongs to decorative and ornamental stones (Smith, 2002), the value of which is determined primarily by decorative properties. A general indicator "decorativeness" usually means a combination of external optical properties, namely color, texture, surface structure. Therefore, the application of techniques for enhancing and improving these qualities in design products from raw gemstones is a promising direction of the art industry.

Art design (Mikhailov and Kuleeva, 1999), which includes the main typology of products made from chalcedony, sets a priority task to identify the aesthetic characteristics of the design object aimed at organizing artistic impressions received from the product. To identify the increased aesthetic value of the design object made of chalcedony, the method 
of using the morphological properties of the material used in the product is used. The key task that needs to be solved during the design of the object is the application of material decorating techniques in order to give the original product an improved useful design form with enhanced aesthetic characteristics. Therefore, the choice of technology for decorating the designed product must be decided in the "material-image-technology" system, and the main goal of modernization is the original and current final image of the product. Harmonization of the design object is achieved by converting the initial parameters of the product with the main means of composition. The proposed methods for changing the decorative characteristics of chalcedony allow changing the image of the product by compositional methods. Artistic and style modification of the image affects the coloristic, graphic and textural organization of the elements of the product's shape, creates emphasis on aesthetically significant, functional, stylistic or semantic components of the product. These changes must be made on the basis of the principles and laws of composition, coloristic, increasing the level of originality and novelty of the product in accordance with modern design trends. The coloristic combination of colors is based on the selected color scheme of matching colors, including saturation and lightness. To create a holistic object, it is necessary to provide the product with the proportionality of the elements, their balance and coordination.

The design feature of lapidary products implies a system of a different approach to stone processing, revealing the chain "shape-texture-color" (Zhukova and Yertsev, 2006; Zhukova and Yertsev, 2006). Figure 1 shows the developed algorithm of actions carried out in the design of art products made of gemstones using methods of changing the color. The objectives of the study include modification of the color of chalcedony, the development of variable technologies for applying structure and texture to its surface. 


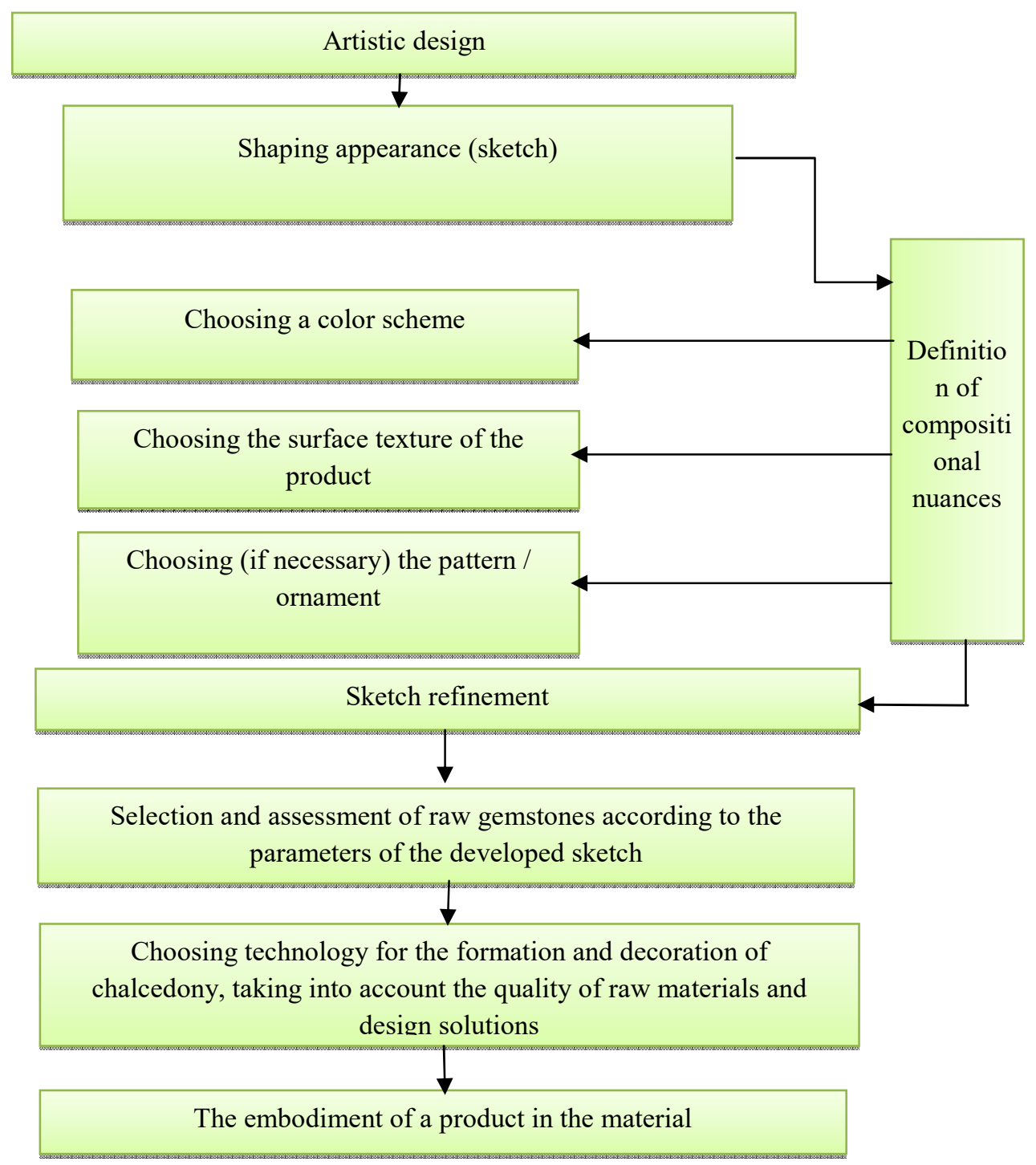

Fig. 1. The developed algorithm of actions carried out in the design of art products made of gemstones using methods of changing the color.

\section{Materials and methods}

The research material was samples of gray translucent chalcedony with a massive texture.

As a research methodology, a systematic approach was used, involving a set of measures to study the subject of the study.

The quantitative characteristics of the artificial color change of chalcedony were obtained by spectrophotometry using a Color I-5 spectrophotometer (Gretag Macbeth Spectroeye, Switzerland).

The surface roughness of chalcedony was determined using an optical profiler by ZeScope company (Zemetrics, USA) with an accuracy of $0.0001 \mu \mathrm{m}$.

Assessment of decorativeness was carried out by organoleptic methods. Processing of the research results was carried out using statistical analysis methods. 


\section{Research results and analysis}

The color change of chalcedony was carried out by heat treatment and the method of impregnation with dyes.

Heat treatment is one of the ways of coloring the stone (Zhukova and Ponomareva, 2013; Ponomareva and Zhukova, 2016), replenishing the natural processes of transforming color centers in the mineral. The samples were heated in the MITERM-8 muffle furnace in the temperature range of $50-500{ }^{\circ} \mathrm{C}$, the heating and cooling rate was $10^{\circ} \mathrm{C} / \mathrm{h}$. The soaking time was in the range from 1 to 20 hours. The temperature intervals that affect the color change were set. Up to $300{ }^{\circ} \mathrm{C}$, color change of the stone was not observed. In the temperature range from 300 to $400^{\circ} \mathrm{C}$, a change in the color of chalcedony occurs. At temperatures above $400{ }^{\circ} \mathrm{C}$, cracks appear on the surface of the stone, leading to the destruction of the material.

Table 1. Color characteristics of changing the color of chalcedony by heat treatment.

\begin{tabular}{|c|c|c|c|c|c|c|c|}
\hline \multirow{2}{*}{$\begin{array}{l}\text { Temperature, } \\
{ }^{\circ} \mathrm{C}\end{array}$} & \multirow{2}{*}{$\begin{array}{c}\text { Soaking time, } \\
\mathrm{h}\end{array}$} & \multirow{2}{*}{ Color } & \multirow{2}{*}{ Image } & \multicolumn{4}{|c|}{$\begin{array}{l}\text { Coordinates of color and } \\
\text { lightness }(\mathrm{x} ; \mathrm{y} ; \mathrm{Y})\end{array}$} \\
\hline & & & & $\begin{array}{c}\lambda, \\
\mathrm{nm}\end{array}$ & $\mathrm{x}$ & $\mathrm{y}$ & Y \\
\hline 350 & 5 & Orange & & 582 & 0.49 & 0.38 & 4.52 \\
\hline 350 & 12 & Brown & & 590 & 0.39 & 0.48 & 4.11 \\
\hline 350 & 20 & White & & - & 0.33 & 0.32 & 15.13 \\
\hline
\end{tabular}

An analysis of the results showed that with an increase in the soaking time of the sample, the color of chalcedony changes. When chalcedony is kept in a temperature range of $300-400{ }^{\circ} \mathrm{C}$ in the time interval from 5 to 20 hours, the color of gray chalcedony changes from orange to brown, gradually forming a white color, i.e. stone discoloration takes place. A limitation of this method is the narrow color range.

Another technology for changing the color of chalcedony is the impregnation method. Coloring of chalcedony by impregnation with a coloring substance is possible due to the presence of pores. The study of the microstructure of chalcedony showed that the pore size is $0.2-0.01$ microns. Changing the color by impregnation was carried out in aqueous solutions of $\mathrm{C} 12 \mathrm{H} 22 \mathrm{O} 11$, aniline dyes and metal salts. The soaking of samples in the coloring solution were carried out at a temperature of $90{ }^{\circ} \mathrm{C}$ for $170 \mathrm{~h}$, because at a temperature of less than $90{ }^{\circ} \mathrm{C}$, the solubility of the dye deteriorates, at a temperature of more than $90^{\circ} \mathrm{C}$, premature dehydration of the coloring solution occurs. The ratio of water to dye was 5:1. At a lower concentration of the dye in the solution, saturated dyeing of chalcedony does not occur. A large concentration makes it difficult to dissolve the dye, which leads to the formation of a precipitate in the solution, which forms a heterogeneous color and forms spotting on the surface of the stone. The compositions of the solutions with metal salts are presented in table 2 , the color chart - in figure 3. 
Table 2. The composition of the solutions for coloring chalcedony by the method of impregnation with metal salts.

\begin{tabular}{|c|c|}
\hline Specified color & Colorants \\
\hline red & - iron (III) oxide followed by firing; \\
\hline brown & $\begin{array}{c}\text { - chrome-oxide IV followed by firing; } \\
\text { - potassium salt of manganese acid; } \\
\text { - hydrochloric acid followed by firing; }\end{array}$ \\
\hline yellow & - iron chloride; \\
\hline blue & $\begin{array}{c}\text { - potassium ferrocyanide followed by boiling in iron sulfate; } \\
\text { - iron (III) oxide, followed by boiling in iron sulfate; }\end{array}$ \\
\hline black & - cobalt nitrate followed by firing; \\
\hline white & - carbon (III) dioxide followed by firing. \\
\hline
\end{tabular}

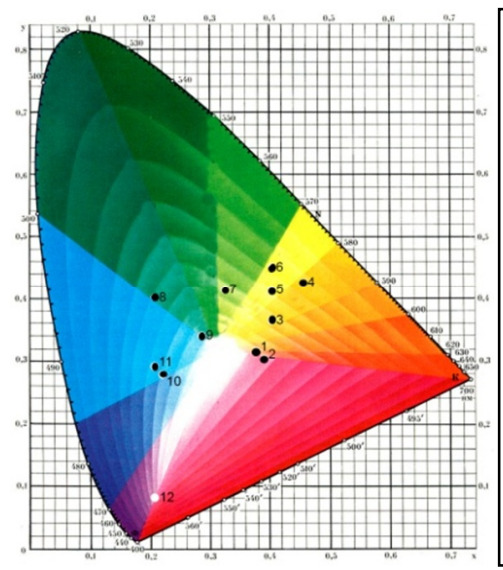
1 - red color (iron (III) oxide solution)
2 - red color (Bordeaux aniline dye solution)
3 - orange color (Orange aniline dye solution)
4 - yellow color (Yellow aniline dye solution)
5 - yellow color (iron chloride solution)
6 - yellow color (water-alcohol solution of iodine)
7 - green color (Green aniline dye solution)
8 - green color (Emerald aniline dye solution)
9 - blue color (Blue aniline dye solution)
10 - blue color (solutions of potassium ferrocyanide and ferrous sulfate)
11 - blue color (solutions of iron (III) oxide and potassium ferrocyanide)

Fig. 2. Color chart with plotted chromaticity coordinates of chalcedony colored by impregnation.

The analysis of the research results presented in Figure 2 showed that the application of the impregnation method provides a wide range of chalcedony colors: red, orange, yellow, green, blue, violet, black, white. The chromaticity coordinates of the obtained colors were determined. Depth of coloring is in the range of $0.5-1.5 \mathrm{~mm}$.

Thus, using the method of heat treatment or impregnation of chalcedony, it is possible to change its color. The given color changing technologies provide uniform surface coloring of the stone (Park, Sohn \& Choi, 2006). It is worth noting that this operation is performed after the final shaping of the product made of chalcedony.

To enhance the decorative effect of a design object made of chalcedony, methods of applying a pattern to a stone surface are also applicable: etching, laser processing, local coloring (Ponomareva, 2017; Ponomareva, 2017).

A study of etching the surface of chalcedony with hydrofluoric acid $40 \%$ was conducted. As a result of applying hydrofluoric acid $40 \%$, a predetermined white pattern is formed on the surface of the stone, contrasting with the main background. With an increase in the time of acid exposure, the roughness of the etched area increases, the dependence of the surface quality on the time of exposure to acid is shown in Figure 3. The results of the study suggest that when the acid is applied for 10-60 minutes, the etched surface is smoother $(\mathrm{Ra}=0.25-0.50 \mu \mathrm{m})$ than with a soaking time of $90-150$ minutes $(\mathrm{Ra}=0.90$ $1.40 \mu \mathrm{m})$. When the stone is exposed to acid for 180 minutes and more, there is a complete dissolution of chalcedony. 


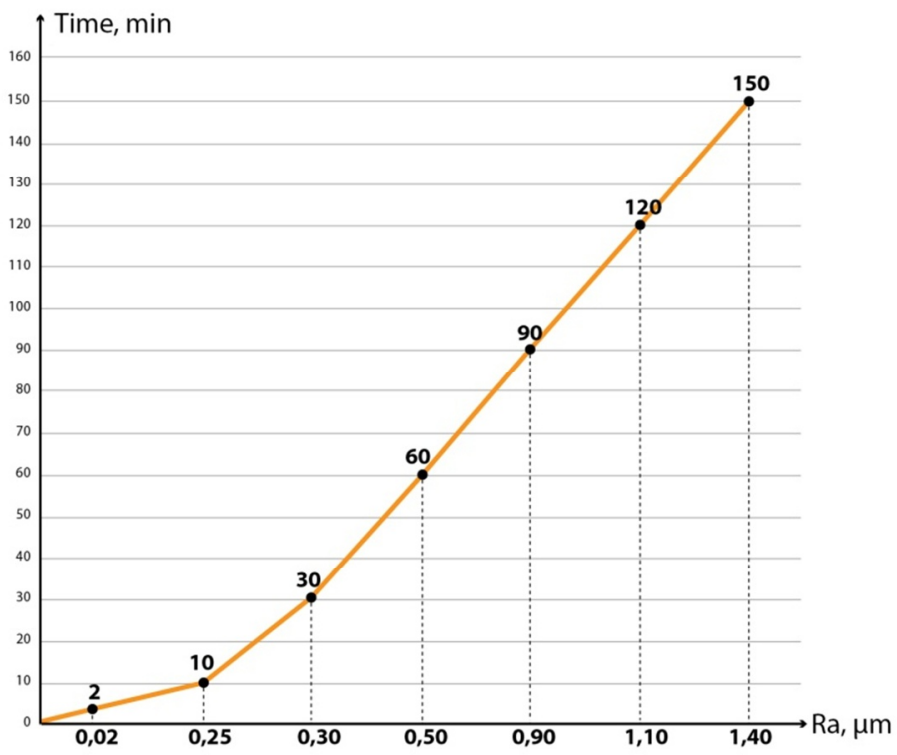

Fig. 3. The dependence of surface quality on the time of treatment of chalcedony with hydrofluoric acid (HF, $40 \%)$.

Another method of applying the pattern is laser processing of chalcedony. The patterning on the surface of chalcedony was carried out by laser processing on a Rabbit HX-6090 machine at a laser power of 70\%, the processing speed varied in the range of 100 - $300 \mathrm{~mm} / \mathrm{s}$, and the beam exposure step was $0.1-0.05 \mathrm{~mm}$. The use of a laser step in the range of $0.1-0.07 \mathrm{~mm}$ and a processing speed in the range of $50-250 \mathrm{~mm} / \mathrm{s}$ do not provide a uniform material removal, the pattern is formed from separate strips. Therefore, the following technological modes of laser processing were determined: the engraving step is $0.05 \mathrm{~mm}$, the processing speed is $300 \mathrm{~mm} / \mathrm{s}$, and the power is $70 \%$. As a result of processing, a uniform white pattern is created on the surface of chalcedony with a massive texture. The quality of chalcedony engraving also depends on the structural features of the mineral, the presence of other mineral inclusions. Partial peeling of the material at the boundary of dissimilar textures was revealed. The use of a preliminary operation of color changing of chalcedony increases the decorative effect of using laser processing of stone.

The use of local impregnation in the dye is another technology for texturing chalcedony, which allows creating a colored pattern on the surface of the stone. An experiment on the impregnation of local areas was carried out in an aniline dye at a temperature of $90{ }^{\circ} \mathrm{C}$, the soaking time was 170 hours. Fluorotex fluoroorganic resin was used as a protective coating, which was removed with acetone after coloring.

The proposed modes of drawing a pattern on the surface of chalcedony allow getting the desired patterns and texture, and will help to expand the aesthetic indicators of stone artwork, conceal surface defects on design objects and recreate the material pattern during the restoration of stone objects.

Another way to enhance the decorativeness of a stone is by texturing the surface (Kukhta, Sokolov, Krauinsh, Kozlova \& Bouchard, 2017). According to the nature of the surface, there are two types: smooth (from rough-finished to mirror-shiny) and relief (with different heights and a diverse nature of the relief), Figure 4. 


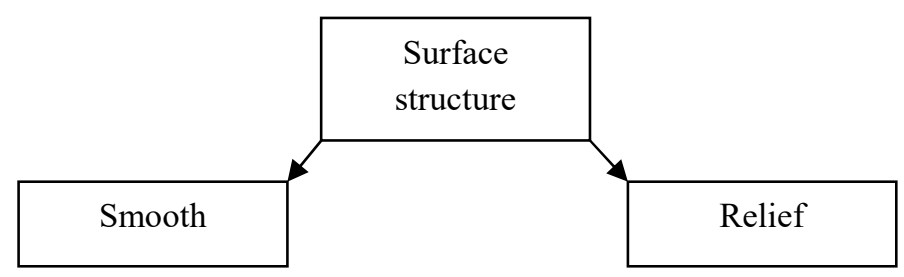

Fig. 4. Types of structure by the nature of the surface.

Various methods for obtaining the surface structure by mechanical means using a variety of tools and abrasive materials of different grain sizes were considered and systematized. The dependence of the surface quality of chalcedony on the technology of finishing processing and the use of tools and auxiliary materials is established, the research results are presented in Figure 5.

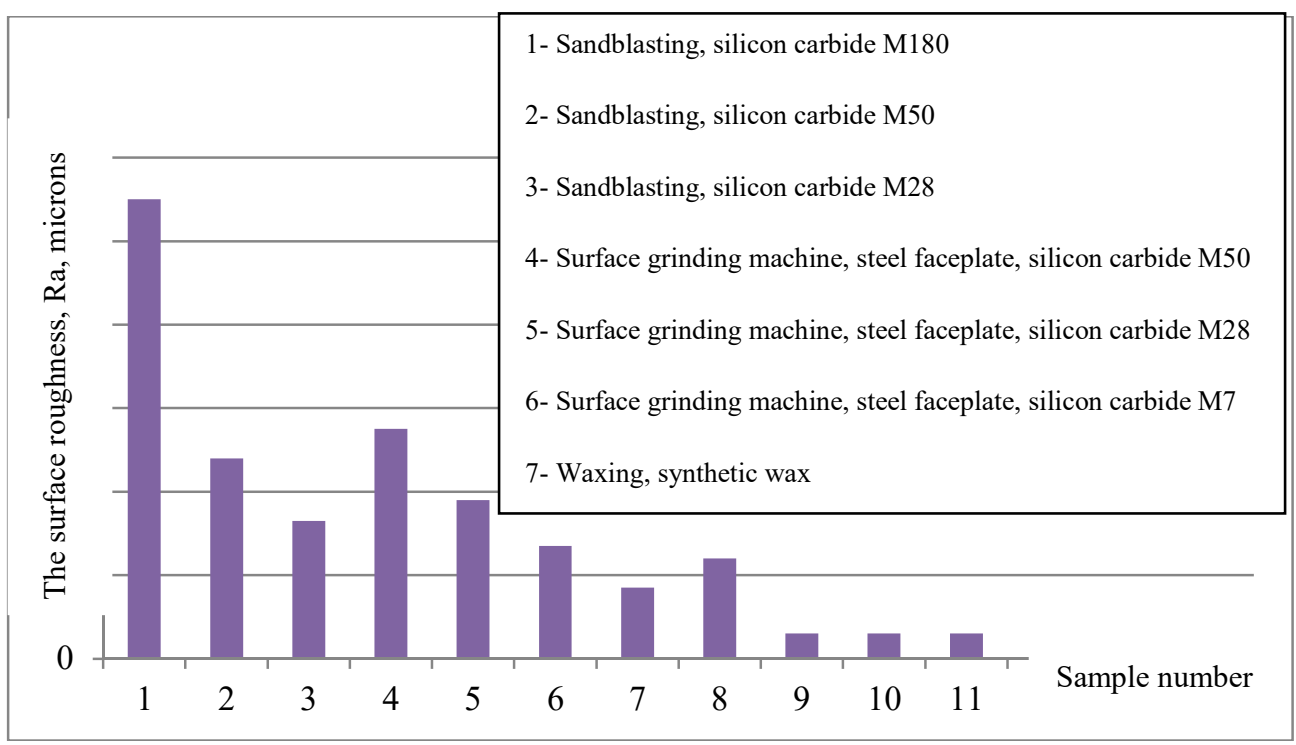

Fig. 5. The dependence of surface quality on the type of processing.

The analysis of the results of studying the surface roughness showed that the achievement of the most uniform matte surface is ensured by sandblasting. Processing samples on a grinding motor using bristle brushes and diamond pastes showed that the use of pastes with a grain size of $20 / 14,14 / 10$ or $5 / 3$ ensures identical surface quality - with a roughness of $\mathrm{Ra} 0.06 \mu \mathrm{m}$, which indicates the interchangeability of these pastes during processing chalcedony surfaces. Similar results were shown by processing with pastes $3 / 2$, 2/1, $1 / 0$ - Ra $0.02 \mu \mathrm{m}$.

The most common types of relief stone texture (Zhukova and Ponomareva, 2014) used in jewelry and figurines were also identified. Relief reflects the nature of the shape, location, size of the bumps on the surface of the material. The following types of relief texture are most often found in figurines: comb, dot texture and imitation of a specific material or type of product (wood, fabric structure, chainmail).

\section{Discussion of the results}

The research results made it possible to create an interactive database "Decorative characteristics of chalcedony", which includes a library of images of developed standards 
made of chalcedony and a description of the technology for obtaining desired surface characteristics by three decorative parameters: color, texture and surface structure. The developed database is verified by a certificate of registration. The database can be used in the design of artwork and jewelry, and also in restoration practice.

\section{Conclusion}

Historically, stone is the most important material of applied art and cultural development of mankind. Therefore, the study of the development and modification of its application - in deposits, in architecture, in stone processing factories and workshops, etc., is an important task of cultural and historical significance. The development of a methodology for modernizing the appearance of design objects from gems through the use of variable compositional combinations of color-structure-texture helps to expand the range of artwork and jewelry products and increase the competitiveness of lapidary products. Decorating the surface of chalcedony is applicable in restoration work in order to replace lost fragments with new-made inserts with specified aesthetic characteristics of the stone surface.

Using the developed methods for decorating the surface of chalcedony will contribute to the expansion of the product design range by modifying the aesthetic characteristics of the material, using low-quality raw gemstones, followed by decorating the stone surface. Depending on the author's idea of the design object, it may be given a different surface character. Complementing the plastic work, surface structure, color and texture help to create an artistic image, being an active expressive means of composition. Thus, the technology of decorating the surface of the stone enhances textural techniques, complement the artistic image, giving the integrity of the product or a realistic interpretation of the form and the plausibility of the pose of the formed object. Decoration of the surface as the final stage of product processing is the most important stage of material processing, due to which the object acquires the final look, and its aesthetic assessment is made by the consumer.

\section{References}

1. R.M. German, Powder injection molding applications to new materials (1998)

2. S. Eyssautier-Chuine, K. Mouhoubi, F. Reffuveille, J.L. Bodnar, Conference on Optics for Arts, Architecture, and Archaeology VII (Munich, Germany, 2019)

3. L.T. Zhukova, V.P. Yertsev, Gemmopolichromiya (to the problem of color formation in the artistic processing of stone) (SPbSUITD, SPb, 2006)

4. L.T. Zhukova, K.S. Ponomareva, Design. Materials. Technology 4(32), 34 - 40 (2014)

5. L.T. Zhukova, K.S. Ponomareva, Design. Materials. Technology 2(27), 54 - 56 (2013)

6. L.T. Zhukova, V.P. Yertsev, Makeup of stone (on the problem of color formation in the artistic processing of stone) (SPbSUITD, SPb, 2006)

7. W. Kautek, Tailoring Structure and Properties 130, 331-349 (2010)

8. S.M. Mikhailov, L.M. Kuleeva, Design basics (New Knowledge, Kazan, 1999)

9. T. Moxon, European Journal of Mineralogy 14(6), 1109-1118 (2002) doi: 10.1127/0935-1221/2002/0014-1109

10. M. O’Donoghue, Quartz (Mir, Moscow, 1990)

11. J.W. Park, C.W. Sohn, B.H. Choi, Current Applied Physics 6(2), 188-193 (2006) doi: 10.1016/j.cap.2005.07.038

12. T. Powolny, M. Dumańska-Słowik, M. Sikorska-Jaworowska, M. Wójcik-Bania, Ore Geology Reviews 114 (2019) doi: 10.1016/j.oregeorev.2019.103130 
13. K.S. Ponomareva, Design. Materials. Technology 3(47), 35-37 (2017)

14. K.S. Ponomareva, "Gemology" conference (Publishing house of Tomsk Central Scientific and Technical Institute, Tomsk, 2017)

15. K.S. Ponomareva, L.T. Zhukova, Design. Materials. Technology 4(44), 20 - 26 (2016)

16. P. Sbornicchia, G. Montesperelli, G.M. Ingo, G. Gusmano, Thermochimica Acta 419(1-2), 195-204 (2004) doi:10.1016/j.tca.2003.12.017

17. G. Smith, Gems (Astrel Publishing house LLC, Moscow, 2002)

18. D. Tiberto, U.E. Klotz, International Conference on Modeling of Casting, Welding and Advanced Solidification Processes 33 (2012)

19. A.E. Fallick, J. Jocelyn, T. Donnelly, M. Guy, C. Behan, Origin of agates in volcanic rocks from Scotland 313(6004), 672-67 (1985) doi: 10.1038/313672a0

20. W. Schumann, Precious and semiprecious stones (BMM CJSC, Moscow, 2010) 